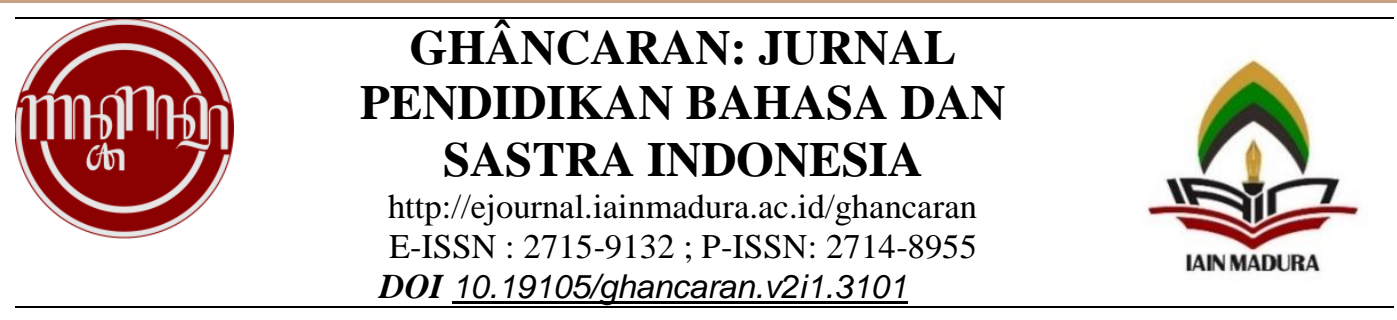

\title{
CAMPUR KODE BAHASA ALAY DI KALANGAN REMAJA SMP TARUNA SURABAYA TIMUR
}

\author{
Dwi Nur Indah Sari*, Juliana $A^{\star \star}$, Bariyadin ${ }^{\star \star \star}$ \\ * Pendidikan Bahasa Indonesia, Universitas Dr. Soetomo \\ ** Pendidikan Bahasa Indonesia, Universitas Dr. Soetomo \\ *** Pendidikan Bahasa Indonesia, Universitas Dr. Soetomo \\ Alamat surel: dwi.nurindahsari@gmail.com
}

\begin{tabular}{l}
\hline \hline \\
\hline Keywords: \\
mixed code; \\
alay \\
language; \\
adolescent \\
language.
\end{tabular}

campur kode;

bahasa alay;

bahasa remaja.

\begin{abstract}
Code mixing is the event of mixing two or more languages in a language situation and there is no one who demands mixing that language. In this study, code mixing is a mixture of elements of the Alay language into Indonesian in the East Taruna Junior High School. This study aims to describe the forms of code mixing that occur in the Youth Language of East Surabaya Junior High School, namely the insertion of elements in the form of alay language in the form of words, phrases, clauses, baster, and word repetition. This research uses qualitative research. Data collection techniques using advanced listening techniques, record techniques, coding techniques, and transcript techniques. The data analysis technique used in this study is the distributional method. The results of data analysis in this study indicate the following: There are 85 insertions of elements in the form of words, there are 13 insertions of elements in the form of phrases, there are 7 insertions of elements in the form of clauses, there are 11 insertions of elements in the form of baster, and there are 16 insertions of elements in the form of words tangible repetition of words in youth dialogue Taruna East Surabaya Middle School. The five elements are represented by a mixture of Alay language and regional languages (Javanese).
\end{abstract}
Abstrak:
Campur kode adalah peristiwa pencampuran dua bahasa atau lebih dalam situasi berbahasa dan tidak ada situa siapapun yang menuntut pencampuran bahasa itu. Pada penelitian ini, campur kode merupakan pencampuran unsur-unsur bahasa alay kedalam bahasa Indonesia padaRemaja SMP Taruna Surabaya Timur. Penelitian ini bertujuan untuk memaparkan wujud-wujud campur kode yang terjadi pada bahasa remaja SMP Taruna Surabaya Timur, yaitu penyisipan unsur bahasa alay yang berwujud kata , frase, klausa, baster, dan pengulangan kata. Penelitian ini menggunakan jenis penelitian kualitatif. Teknik pengumpulan data menggunakan teknik simak lanjutan, teknik rekam, teknik pengkodean, dan teknik transkrip. Teknik analisis data yang dipergunakan dalam penelitian ini adalah metode distribusional. Hasil analisis data dalam penelitian ini menunjukkan hal-hal berikut: Terdapat 85 penyisipan unsur yang berwujud kata, terdapat 13 penyisipan unsur yang berwujud frase, terdapat 7 penyisipan unsur yang berwujud klausa, terdapat 11 penyisipan unsur yang berwujud baster, dan terdapat 16 penyisipan unsur yang berwujud perulangan kata dalam dialog remaja SMP Taruna Surabaya Timur. 
Lima unsur tersebut terwakili oleh campur kode bahasa alay dan bahasa daerah (Jawa).

Terkirim : 2 Maret 2020; $\quad$ Revisi: 8 Mei 2020; $\quad$ Diterima: 22 Juli 2020

OGhâncaran: Jurnal Pendidikan Bahasa dan Sastra Indonesia

Tadris Bahasa Indonesia

Institut Agama Islam Negeri Madura, Indonesia

\section{PENDAHULUAN}

Pada umumnya, manusia menggunakan bahasa sebagai alat komunikasi. Melalui bahasa, kita dapat memberikan atau memperoleh informasi dari berbagai sumber. Bahasa juga dapat mendeskripsikan suatu peristiwa yang dilakukan oleh suatu individu atau kelompok(Aslinda dan Syafyahya, 2007). Salah satu bahasa yang kita gunakan setiap hari adalah bahasa Indonesia. Namun, perlu diketahui di Indonesia banyak sekali ragam bahasa daerah yang dipandang sebagai warisan dan kekayaan bangsa (Chaer \& Agustina, 2010). Keberagaman itu menjadikan Indonesia sebagai Negara yang beragam akan ciri khas yang dimilikinya.

Bahasa Indonesia berhasil mendudukan diri sebagai bahasa budaya dan bahasa ilmu. Pada praktiknya, dua dua kedudukan tersebut dapat muncul secara bersamasama atau salah satunya. Bahasa Indonesia sebagai bahasa resmi bukan hanya digunakan oleh pemerintah untuk berkomunikasi dengan masayarakat luas, bukan pula sebagai alat komunikasi antar daerah atau suku melainkan sebagai alat untuk berbagi informasi mengenai kegiatan pemerintahan atau kegiatan formal yang lain.Sebelum menggunakan bahasa Indonesia, sebagian besar masyarakat menggunakan bahasa daerah guna menyampaikan informasi kepda setiap orang yang dikehendakinya. Salah satu yang dapat kita jumpai adalah penggunaan berbagai bahasa Alay yang ada pada SMP Truna. Penggunaan bahasa ini sangat intens digunakan karena kepekaan mereka dalam memahami bahasa tersebut. Sehingga, mungkin bagi orang awa tidak akan baham dengan apa yang diucapkan para siswa di SMP Taruna.

Bahasa yang digunakan kalangan Remaja SMP Taruna Surabaya Timur termasuk sosiolek, karena bahasa ini sering digunakan para Remaja SMP Taruna Surabaya Timur agar terlihat lebih modern dan diakui oleh teman - temannya. Sosiolek yakni variasi bahasa yang terkenal dengan status golongan dan kelas sosial para penuturnya (Chaer \& Agustina, 2004). Sosiolek adalah variasi bahasa yang digunakan oleh masyarakat akibat adanya perbedaan kelompok sosial, kelompok cendekiawan, remaja, orang tua, dan sebagainta. Sosiolek juga muncul akibat adanya status, golongan, dan kelas sosial penuturnya.

Sosiolek merupakan suatu variasi dari bahasa yang disebabkan oleh perbedaan kelompok sosial tertentu dalam lingkungan masyarakat, seperti kelompok cendekiawan, pengusaha, pegawai, remaja, orang tua, dan lain sebagainya. Sosiolek juga merupakan suatu variasi bahasa yang disebabkan oleh status, golongan, dan kelas sosial penuturnya. Variasi jenis ini juga menyangkut masalah pribadi penuturnya, seperti usia, pekerjaan, tingkat kebangsawanan, dan juga keadaan sosial ekonomi. Misalnya, perbedaan usia, biasa melihat perbedaan variasi bahasa yang digunakan oleh anak anak, para remaja, orang dewasa, dan orang - orang tergolong lanjut usia. Penelitian kali ini mengungkap adanya campur kode dalam bahasa alay yang ada di SMP Taruna.

Campur kode juga dapat diartikan sebagai bentuk pemakaian dua varian bahasa dalam suatu situasi tertentu. Campur kode menitik beratkan pada penggunaan atau pemakaian suatu bahasa kedalam bahasa lain berdasarkan situasi tertentu bertujuan untuk memperluas gaya atau memperindah situasi tutur. Campur kode lebih menitik beratkan pada pecampuran dua bahasa atau lebih yang kerapkali diucapkan oleh penuturnya sesuai dengan situasi yang dialaminya ((Nababan, 1991). Kurniawati juga mennyatakan bahwa campur kode juga dapat didefinisikan sebagai keadaan bahasa yang digunakan oleh seseorang dengan cara mencampur adukkan dua bahasa atau 
lebih dalam bertutur kata dari mulai tingkat kata sampai klausa (Sukoyo, 2010). Pada saat ini, dalam lingkungan pergaulan telah dikenal dan berkembang bahasa Alay yang digunakan pada kalangan Remaja SMP Taruna Surabaya, bahasa Alay merupakan salah satu bahasa yang digunakan oleh remaja agar lebih terlihat modern dan diakui oleh teman- temannya. Contohnya, "Ciyus ?", "Miapah ?", yang berarti "Serius ?", "Demi apa ?" (Ningrat, 2012)

Sebagian besar siswa SMP di wilayah Surabaya Timur kerapkali menggunakan bahasa atau kalimat yang unik ketika ia berbahasa Indonesia. Banyak bahasa-bahasa Alay yang tercampur di dalamnya. Hal ini tidak terasa, bahwa semakin banyak remaja menggunakan bahasa tersebut untuk berkomunikasi. Danie (Chaer \& Agustina, 2010) mengungkapkan bahwa pemakaian beberapa bahasa Indonesia di SMP Taruna Surabaya adalah karena Karena penggunaaan bahasa Alay lebih dipadang bergengsi daripada penggunaan bahasa Indonesia sebagai bahasa nasional. Oleh karena itu, penelitian kali ini mengungkapkan berbagai macam bahasa Alay guna memberikan pengetahuan kepada para generasi muda agar berusaha untuk menggunakan bahasa yang baik dan benar. Dengan demikian, kita telah menjunjung tinggi bahasa Indonesia sebagai bahasa nasional yang memiliki martabat bagi bangsa Indonesia.

Hasil penelitian terdahulu merupakan referensi bagi peneliti untuk melakukan penelitian ini. Dalam penelitian tersebut terdapat kesamaan permasalahan penelitian Skripsi oleh Rini Maryani yang dibuat pada tahun 2011 yang berjudul analisis campur kode dalam novel "Ketika Cinta Bertasbih" karya Habiburrahman El Shirazy bertujuan mendiskripsikan wujud campur kode dan fungsi campur kode dalam novel "Ketika Cinta Bertasbih" karya Habiburrahman El Shirazy. Berdasarkan analisis dalam novel "Ketika Cinta Bertasbih" karya Habiburrahman El Shirazy di dapati campur kode bahasa daerah (Jawa) dan bahasa asing (Arab dan Inggris) berjumlah 219 data (Malyani, 2011). Selanjutnya penelitian yang dilakukan oleh Masitoh (2013) dengan judul "Campur Kode Bahasa Indonesia Ke Dalam Bahasa Jawa Pada Siaran Radio Jampi Sayah Di Radio Skb Pop Fm Gombong". Pada penelitian tersebut berhasil lima jenis campur kode diantaranya yaitu kata, frasa, baster, pengulangan kata, idiom dan klauasa (Masitoh, 2013). Sementara perbedaan antara peneilitian yang dilakukan sebelumnya terletak pada kajian yang diambil oleh peneliti adalah Campur Kode Bahasa Alay di Kalangan Remaja SMP Taruna Surabaya Timur.

\section{METODE}

Jenis penelitian yang digunakan dalam penelitian ini adalah penelitian deskriptif dengan pendekatan kualitatif. Peneliti menggunakan penelitian deskriptif dengan pendekatan kualitatif karena penelitian ini berupa campur kode yang berupa bahasa Alay yang digunakan Kalangan Remaja SMP Taruna Surabaya. Penelitian ini menggunakan pendekatan deskriptif karena penelitian ini mendiskripsikan atau menjabarkan campur kode bahasa alay pada Kalangan Remaja SMP Taruna Surabaya Timur. Data yang digunakan dalam penelitian ini adalah berupa data kalimat alay yang ada dalam dialog yang diucapkan oleh para remaja SMP Taruna Surabaya Timur yang mengalami campur kode. Sumber data dalam penelitian ini adalah semua data dan informasi yang diperoleh dari tuturan siswa- siswi SMP Taruna Surabaya Timur kurang lebih 60 siswa. Penelitian ini dilaksanakan pada saat istirahat atau jam kosong. Teknik pengumpulan data menggunakan teknik simak lanjutan, teknik rekam, teknik pengkodean, dan teknik transkrip. Teknik analisis data yang dipergunakan dalam penelitian ini adalah metode distribusional. Metode distribusional adalah metode yang digunakan untuk tujuan-tujuan analisis struktur wacana secara internal, wacana (konteks). Wacana sebagai struktur yang dipresentasikan oleh serangakaian kalimat, perlu diuraikan kesatuan dan keruntutan alur maknanya. Teknik untuk menganalisis pola 
keruntutan itu ialah dengan penerapan teknik permutasi (balik) dan teknik substitusi (ganti).

\section{HASIL DAN PEMBAHASAN}

Analisis penelitian berupa wujud campur kode yang sebelumnya telah disebutkan terdapat lima jenis penyisipan wujud campur kode, yaitu : penyisipan kata, penyisipan frase, penyisipan klausa, penyisipan baster, dan penyisipan perulangan kata. Data yang terkumpul tidak semua dianalisis, analisis hanya dilakukan terhadap sebagian data yang dianggap mewakili dari seluruh data yang peneliti ambil yaitu tuturan siswa - siswi SMP Taruna Surabaya Timur. Berikut ini hasil analisis data pada penelitian.

1. Bentuk penyisipan kata Kata Bahasa Alay

\begin{tabular}{|l|l|l|}
\hline \multicolumn{2}{|c|}{ Kata } \\
\hline Kuerens (keren) & Asiapppp (siap) & Jutek (judes) \\
\hline Ciyus (serius) & yak (iya) & Alow Oposisi enak)(halo) \\
\hline syantikk (cantik & Asiapppp (siap) & Pewe (posisi enak) \\
\hline lebay (berlebihan) & ember (memang) & jijay (jijik) \\
\hline Cus (ayo) & Sumpeh(sumpah) & selon (santai) \\
\hline aje (saja & gabut (tidak ada kegiatan) & halokes (sekolah) \\
\hline ue (aku & cucok(cocok) & cemungut (semangat) \\
\hline bo.ong (bohong) & Bete (bosan) & beut (banget) \\
\hline keles (kali) & Be terciduk (tertangkap) te & culit (sulit) \\
\hline peres (palsu) & Enelan (beneran) & julid (iri hati) \\
\hline Bingit (banget) & Pewe (posisi enak) & ewul (lapar) \\
\hline tubir (ribut) & prikitiu (ciye) & endang (enak) \\
\hline sotoy (sok tau) & sekong (gay) & boil (mobil) \\
\hline gercep (cepat) & cacamarica (cari) & maaci (terima kasih) \\
\hline Sans (santai) & Seperatus (sepatu) & \\
\hline
\end{tabular}

Tabel 1. Kata Bahasa Alay

2. Bentuk penyisipan frase bahasa alay

\begin{tabular}{|l|l|}
\hline \multicolumn{2}{|c|}{ Frase } \\
\hline Mi apah (demi apa) & kids jaman now (anak jaman sekarang) \\
\hline generasi micin (Melakukan hal bodoh atau gila): & Ma capah (sama siapa) \\
\hline auto missqueen (otomatis miskin) & khan maen (bukan main) \\
\hline kam seupay (kampungan sekali) & soraya perucha (sakit perut) \\
\hline
\end{tabular}

Tabel 2. Frase Bahasa Alay

3. Bentuk penyisipan klausa bahasa alay

\begin{tabular}{|l|l|}
\hline \multicolumn{2}{|c|}{ Klausa } \\
\hline akikah njajan dulu (aku jajan dulu) & akikah belalang seperatus (aku beli sepatu) \\
\hline akikah dolen (aku main) & ayas ngalup halokes (saya pulang sekolah) \\
\hline akikah makan dulu (aku makan dulu) & \\
\hline Ayas males (aku malas) & \\
\hline
\end{tabular}

Tabel 3. Klausa Bahasa Alay

\section{Bentuk penyisipan baster bahasa alay}

\begin{tabular}{|l|l|}
\hline \multicolumn{2}{|c|}{ Klausa } \\
\hline ngegas (sindiran) & Nyacat (cerewert) \\
\hline Nyuantai (santai) & ngayasuk (sayangku) \\
\hline Ngakak (terbahak-bahak) & Ngaps (lagi apa) \\
\hline Ayas males (aku malas) & \\
\hline
\end{tabular}

Tabel 4. Klausa Bahasa Alay 


\begin{tabular}{|l|l|}
\hline \multicolumn{2}{|c|}{ Klausa } \\
\hline cabe-cabean (remaja putri yang nakal) & ihdup-ihdup (hidup-hidup) \\
\hline terong-terongan (remaja putra yang nakal) & pucing-pucing (pusing-pusing) \\
\hline unyu-unyu (lucu-lucu) & muyus-muyus (mulus-mulus) \\
\hline lekong-lekong (banci-banci) & malah-malah(marah-marah) \\
\hline muyes-muyes (mules-mules) & unch-unch (imut-imut) \\
\hline bayeng-bayeng (bareng-bareng) & cama-cama(sama-sama \\
\hline
\end{tabular}

Tabel 5. Perulangan Kata

\section{Pembahasan}

Campur kode merupakan situasi penggunaan bahasa kedalam bahasa lain. Hal ini juga dapat dikatakan sebagai pencampuran bahasa. Campur kode dapat dinyatakan pemakaian dua bahasa atau lebih atau dua varian bahasa dalam suatu situasi tertentu. Campur kode terjadi apabila seorang penutur menggunakan bahasa secara dominan untuk mendukung suatu tuturan yang disisipi dengan unsur bahasa lain. Gejala campur kode ini biasanya terkait dengan karakteristik penutur, misal latar belakang sosial, pendidikan, dan kepercayaan. Setidaknya ada dua hal yang paling melatar belakangi penggunaan campur kode. Faktor pendorong terjadinya campur kode oleh Suwito (dalam Maulidini, 2007) dapat dibedakan atas latar belakang sikap (atitudinal type) atau nonkebahasaan dan latar belakang kebahasaan (linguistic type). Penelitian ini mendiskripsikan atau menjabarkan campur kode bahasa alay pada Kalangan Remaja SMP Taruna Surabaya Timur. Penggunaan campur kode dalam Bahasa Alay di Kalangan Remaja SMP Taruna di Surabaya Timur berupa wujud campur kode meliputi lima penyisipan unsur-unsur antara lain:

a. Penyisipan unsur-unsur berwujud kata berjumlah 44 data

Salah satu campur kode bahasa alay yang berwujud kata ialah kuerens. Tuturan ini terdapat campur kode, karena kata "kuerens" merupakan dialek orang alay yang mendapat penambahan kata " $u$ " dan "s" sehingga pada kalimat ini bahasa Alay menyisip pada bahasa Indonesia. Sehingga kata "kuerens" dalam kalimat termasuk campur kode penyisipan kata. Kata merupakan satuan terkecil yang dapat diujarkan sebagai bentuk yang bebas atau berdiri sendiri. Kata "kuerens" dalam bahasa Indonesia yaitu "keren".

b. Penyisipan unsur-unsur berwujud frase berjumlah 8 data

Salah satu campur kode bahasa alay berwujud frase adalah kam seupay. Tuturan ini terdapat campur kode, karena "kam seupay" merupakan kata dari bahasa alay. Dalam kalimat ini bahasa alay menyisip pada bahasa Indonesia. Frase "kam seupay" dalam kalimat ini termasuk campur kode penyisipan Frase. Frase merupakan kelompok kata nonpredikatif, bukan kata majemuk, dan bukan klausa atau kalimat. Frase "kam seupay" dalam bahasa Indonesia yaitu "kampungan sekali"

c. Penyisipan unsur-unsur berwujud klausa berjumlah 6 data

Salah satu campur kode berwujud klausa yaitu "akikah njajan dulu". Tuturan ini terdapat campur kode, karena "akikah njajan dulu" merupakan Klausa dari bahasa alay. Dalam kalimat ini bahasa alay menyisip pada bahasa Indonesia. Klausa "akikah njajan dulu" dalam kalimat ini termasuk campur kode penyisipan klausa. Klausa merupakan gabungan kata yang unsurnya menduduki fungsi sintaksis atau gabungan kata yang bersifat predikatif yang belum memiliki intonasi final. Klausa "akikah njajan dulu" dalam bahasa Indonesia yaitu "aku jajan dulu"

d. Penyisipan unsur-unsur berwujud baster berjumlah 6 data

Salah satu campur kode bahasa Alay yang berwujud baster adalah "ngegas". Tuturan ini terdapat campur kode, karena "ngegas" merupakan Baster dari bahasa alay. Dalam kalimat ini bahasa alay menyisip pada bahasa Indonesia. Baster "ngegas" dalam 
kalimat ini termasuk campur kode penyisipan baster. Baster merupakan hasil perpaduan dua unsur bahasa yang berbeda bentuk satu makna. Baster "ngegas" dalam bahasa Indonesia yaitu "sindiran"

e. Penyisipan unsur-unsur berwujud perulangan kata berjumlah 12 data

Contoh campur kode yang mengandung unsur campuran yaitu cabe-cabean". Tuturan ini terdapat campur kode, karena "cabe-cabean" merupakan Perulangan kata dari bahasa alay. Dalam kalimat ini bahasa alay menyisip pada bahasa Indonesia. Perulangan kata "cabe-cabean" dalam kalimat ini termasuk campur kode penyisipan perulangan kata. Perulangan kata merupakan kata yang terjadi sebagai akibat dari reduplikasi. Perulangan kata "cabe-cabean" dalam bahasa Indonesia yaitu "anak ABG cewek yang nakal"

Penggunaan campur kode dalam Bahasa Alay di Kalangan Remaja SMP Taruna di Surabaya Timur berupa jenis campur kode meliputi satu jenis campur kode antara lain jenis campur kode yaitu bahasa Alay berjumlah 76 data

\section{SIMPULAN}

Pada bagian akhir ini, penulis akan memaparkan kesimpulan yang diambil yang di dasarkan pada temuan hasil Penelitian ini menggunakan campur kode dalam Bahasa Alay di Kalangan Remaja SMP Taruna di Surabaya Timur menghasilkan beberapa kesimpulan, campur kode di Kalangan Remaja SMP Taruna di Surabaya Timur berupa wujud campur kode meliputi lima penyisipan unsur-unsur antara lain penyisipan unsir berwujud kata, berwujud frase, klausa, baster, dan perulangan dengan total 76 data.

\section{DAFTAR RUJUKAN}

Aslinda dan Syafyahya, L. (2007). Pengantar Sosiolinguistik. Bandung: Refika Aditama. Chaer, A., \& Agustina, L. (2004). Sosiolinguistik:Perkenalan Awal. Jakarta: Rineka Cipta.

Chaer, A., \& Agustina, L. (2010). Pengantar Awal liguistik. Jakarta: Rineka Cipta.

Malyani, R. (2011). Analisis Campur Kode Dalam Novel "Ketika Cinta Bertasbih" Karya Habiburrahman El Shirazy. UIN Jakarta.

Masitoh, S. (2013). CAMPUR KODE BAHASA INDONESIA KE DALAM BAHASA JAWA PADA SIARAN RADIO JAMPI SAYAH DI RADIO SKB POP FM. Jurnal Pendidikan, Bahasa, Sastra, Dan Budaya Jawa Universitas Muhammadiyah Purworejo, 03(01), 28-33.

Nababan, P. W. . (1991). Sosiolinguistik Suatu Pengantar. Jakarta: Gramedia Pustaka Utama.

Ningrat, K. (2012). Pengaruh Bahasa Alay. Retrieved January 27, 2019, from http.//siimute.blogspot.com/2012/pengaruh-bahasa-alay-terhadap.html.

Moleong, Lexy J. 2013. Metode Penelitian Kualitatif. Edisi Revisi. Bandung : PT. Remaja Rosdakary

Sukoyo, J. (2010). ALIH KODE DAN CAMPUR KODE PADA TUTURAN PENYIAR

ACARA CAMPURSARI RADIO PESONA FM. Lingua, 6(2-8). 